DOI: 10.12731/2227-930X-2017-2-9-25

УДК 721.01

\title{
РАЗВИТИЕ ВЫСОТНОГО СТРОИТЕЛЬСТВА В ГОРОДАХ С ЧИСЛЕННОСТЬЮ НАСЕЛЕНИЯ ОТ 250 ДО 500 ТЫСЯЧ ЖИТЕЛЕЙ (НА ПРИМЕРЕ ГОРОДОВ УРАЛЬСКОГО ФЕДЕРАЛЬНОГО ОКРУГА)
}

\section{Шенцова О.М., Федосихин В.С.}

В статье рассматриваются история возведения высотных зданий, особенности восприятия высотных зданий в городской среде, какие факторы влияют на выбор места строительства высотных зданий. Раскрываются такие понятия, как «высотный дом», «выссотная доминанта». Также, приводится анализ наличия высотных зданий крупных городов с численностью населения от 250 до 500 тысяч жителей Уральского Федерального округа: Кургана, Нижнего Тагила, Нижневартовска, Сургута и Магнитогорска. А также дан анализ градостроительной ситуации 2. Магнитогорска, где выявлены возможные, наиболее вероятные и предлагаемые места для расположения высотных зданий на пересечении или завершении осей улиц.

Цель работы - анализ высотного строительства в крупных городах Уральского Федерального округа с численностью населения от 250 до 500 тысяч жителей.

Метод или методология проведения работы: в статье использовались методь теоретического и визуального анализа, наблюдения, а также изучение литературных и интернет источников.

Результаты: получен систематизированный теоретический материал в области архитектуры и градостроительства городов Уральского Федерального округа.

Область применения результатов: полученные результаты могут быть применены в области архитектурного образования и практической архитектурной деятельности. 
Ключевые слова: высотные здания; высотное строительство; городская среда.

\section{DEVELOPMENT OF HIGH-RISE CONSTRUCTION IN THE CITIES WITH POPULATION FROM 250 TO 500 THOUSAND INHABITANTS (ON THE EXAMPLE OF THE CITIES OF THE URAL FEDERAL DISTRICT)}

\section{Shentsova O.M., Fedosihin V.S.}

In article history of construction of high-rise buildings, features of perception of high-rise buildings in the urban environment what factors influence the choice of the site of high-rise buildings are considered. Such concepts as "skyscraper", "a high-rise dominant" reveal. Also, the analysis of existence of high-rise buildings of the large cities with population from 250 to 500 thousand residents of the Ural Federal District is provided: Barrow, Nizhny Tagil, Nizhnevartovsk, Surgut and Magnitogorsk. And also the analysis of a town-planning situation of Magnitogorsk where the possible, most probable and offered places for an arrangement of high-rise buildings on crossing or end of axes of streets are revealed is given.

Work purpose - the analysis of high-rise construction in the large cities of the Ural Federal District with population from 250 to 500 thousand inhabitants.

Method or methodology of carrying out work: in article methods of the theoretical and visual analysis, observation, and also studying literary and the Internet of sources were used.

Results: the systematized theoretical material in the field of architecture and town planning of the cities of the Ural Federal District is received.

Scope of results: the received results can be applied in the field of architectural education and practical architectural activities.

Keywords: high-rise buildings; high-rise construction; urban environment. 
История возведения высотных зданий начинается с конца XIX в. Первые высотные сооружения были воздвигнуты в США, а через десятки лет стали появляться в странах Западной Европы и Азии. Главной причиной строительства зданий большой этажности явилась высокая ценовая политика на земельные ресурсы, рост населения и плотность застройки в городах, имеющих ограниченные возможности в дальнейшем расширении границ города.

Высотный дом являет собой отдельно стоящее объемное сооружение, которое является «градостроительной доминантой» в архитектурной среде города. Понятие «высотная доминанта» имеет следующее значение - «высокие объекты с ярко выраженной вертикальной направленностью, формирующие силуэт города и являющиеся главными объектами в окружающем их пространстве, зрительные ориентиры, которые направляют внимание наблюдателя на главный структурный элемент города, а также иллюзорно увеличивают или уменьшают глубинность городского пространства» [14]. Высотное здание или сооружение всегда выступает в роли знакового элемента-ориентира. Это как символ или «визитная карточка» города.

Рекомендации к проектированию высоток, как наиболее сложным объектам строительства, принимаются международными общественными организациями инженеров и архитекторов IABCE - ASCE и CIB.

Благодаря проводимым симпозиумам по проблеме высотного строительства сооружения высотой до 30 м относятся к зданиям повышенной этажности, до 50, 75 и 100 метров, соответственно, к I, II и III категориям многоэтажных зданий, свыше 100 м - к высотным.

В Германии действует классификация высотных зданий, включающая следующие группы: I - здания высотой 22-30 м, II - 3060 м, III - выше 60 м и IV - выше 200 м. При этом правила прописаны для первых трех групп, а четвертая группа в резерве. Других сведений о классификациях высотных зданий, требований к их проектированию и их определения в других странах не имеет- 
ся. В кодах США, DIN в Германии, EU в Европе и в нормах по строительству других развитых стран нормативы по высотному домостроению отсутствуют. К высотным зданиям в России причисляются дома выше 75 метров (общественные объекты - выше 50 м), но ниже 120-150 метров [10].

Возвышающиеся в пространстве элементы могут стать пространственными ориентирами в случаях: если элемент виден с разных направлений города, если имеет резкий контраст с находящимися по соседству зданиями и сооружениями за счет размещения или высотности. Такие ориентиры могут быть индивидуальными, изолированными от других сооружений высотными объемами, так и объемами, подкрепленными другими объектами городской среды.

Высотные вертикальные объемы как правило завершают какую либо градостроительную ось, являются центром городского пространства, являются фокусирующим композиционным центром, который собирает окружающую городскую застройку в единое целое.

Возведение высотных зданий включает в себя не только сам процесс возведения, но и большой комплекс задач, связанных с этим процессом. При выборе места высотного строительства необходимо учитывать факторы, обусловленные градостроительной ситуацией, архитектурными особенностями прилегающей застройки.

\section{Влияние высотных зданий \\ на восприятие городской среды}

В городской среде высотные здания являются акцентами из-за контраста по отношению к преобладающей застройки от 9 до 16 этажей и оказывают большое влияние на восприятие городской среды. Поэтому к высоткам предъявляются особые требования, обеспечивающие повышение эстетики городской среды.

В основе здания лежит вертикальное развитие объема здания, а геометрия формы здания может быть как простой так и слож- 
ной. Последние преобладают в мировой архитектуре. Таких, как известные высотные здания в Дубаи (ОАЭ), имеющие сложные геометрические объемы.

Важное значение при визуальном восприятии объема высотного здания имеет то, что этот объем мы воспринимаем снизу вверх, не видя крыши. Поэтому одним из архитектурных приемов является создание выразительного завершения вертикального объема (крыши в виде куполов, шатров, пирамид, шпилей).

Восприятие зданий и влияние его композиционных особенностей на зрителя зависят от расстояния до них от точки наблюдения. Для полного восприятия высотного здания зритель должен находиться на расстоянии от объекта равном его двум или трем его высотам, т.е. с дальней перспективы. Чем ближе расстояние к зданию, тем лучшее восприятие происходит более мелких деталей здания. В связи с этим рекомендуется наиболее крупные членения и детали располагать в верхней и средней частях здания, а более мелкие детали - в нижней части. Высотное здание играет важную композиционную роль в городской среде, если визуально наблюдается не менее 1/3 высоты основной высоты сооружения.

И, наконец, объем здания, фасады, их художественное решение должны раскрывать функциональное назначение здания. В первом случае, сооружения могут восприниматься как общедоступным объектом (развлекательны комплекс, жилое задание и т.п.) или официальный центр (офисный, торговый или административный центр), во втором случае, могут восприниматься как неприступный объект (банк), при этом создается психологическая дистанция между зрителем и объектом. Наряду с перечисленными факторами, влияющими на восприятие высотных зданий в городской среде, большую и функциональную роль играет цвет и освещение, усиливающие выразительность объекта.

Что же касается колористики высотных зданий, то в отличие от малоэтажных зданий, которые требуют крупных ритмичных цветовых членений, высотные здания в большинстве своем не 
требуют интенсивного цветового решения. Поэтому их цвет, как правило, совпадает с естественным цветом используемых материалов (металл, стекло и т.п.).

\section{Анализ высотного строительства в городах Уральского Федерального округа с населением до 500 тыс. жителей}

Уральский Федеральный (УрФО) округ состоит из:

- 2 города-миллионера,

- 1 крупнейший (от 500 тыс. до 1 млн жителей),

- 5 крупных (от 250 тыс. до 500 тыс. жителей),

- 8 больших (от 100 тыс. до 250 тыс. жителей),

- 17 средних (от 50 тыс. до 100 тыс. жителей),

- 82 малых (менее 50 тыс. жителей).

К пяти крупным городам УрФО с численностью населения (данные на 2016 г.) относятся такие как г. Курган (Курганская обл.) - 385189 жителей, г. Нижний Тагил (Свердловская обл.) 361883 жителей, г. Нижневартовск (Ханты-Мансийский автономный округ - Югра) - 270860 жителей, г. Сургут (Ханты-Мансийский автономный округ - Югра) - 306703 жителей, г. Магнитогорск (Челябинская обл.) - 408401 жителей [3].

Дата основания города Курган на реке Тобол по представлению профессора В.В. Менщикова считается 1679 год. Площадь города составляет 0,39 тысяч кв.км. Развитие строительства получило толчок в 1943 г.после становления города административным центром Курганского округа. В это время активно строятся общественные здания.

Сегодня г. Курган насчитывает несколько зданий повышенной этажности. Наиболее привлекательные для нас:

- жилой 16-ти этажный дом «Добрый дом», который был начат в 2012 г. по проекту Российской компании «Смарт Лоджистик Групп - Девелопмент» и сдан в эксплуатацию в 2016 г.

- жилой комплекс «Эверест», состоящий из группы зданий 18-ти и 19-ти этажных панельных домов и расположенный 
на первой линии проспекта М. Голикова самый высокий объект в г. Кургане.

Сегодня на обсуждении в мэрии проект строительства 25-ти этажного жилого дома в центре Кургана, который станет самым высоким в городе. Однако проект вызвал противоположные мнения, в том числе отрицательное мнение архитекторов города. Они считают, что необходимо учесть, что рядом с местом планируемого строительства находится очень важная градостроительная доминанта - Богоявленский кафедральный собор. Исторически сложилось, что высота зданий вблизи храмов и церквей не должна быть визуально выше оснований куполов [5].

Город Нижнний Тагил основан в 1722 г. и считается вторым по величине городом Свердловской области. Водная артерия района - река Тагил с множеством притоков. Площадь города 298 кв.км. до 2008 г., 4106 кв. км. после 2008 г. после присоединения 22 сельских поселений.

Нижний Тагил это город с устоявшейся горно-обогатительной и металлургической промышленностью, крупный торговый, спортивный, культурный центр. В окрестностях города Нижний Тагил расположены горнолыжные комплексы и лыжные трассы, на которых проводятся международные соревнования. Архитектурный облик города сформировался в XVIII-XIХв.в. в виде памятников архитектуры конструктивизма, советского классицизма, хрущевского аскетизма. Облик города и начал меняться в ХХв. и приобрел новое архитектурное звучание.

В 1980-1990 г.г. появились первые многоэтажные дома в районе железнодорожного вокзала, высотные доминанты, которые сформировали так называемое «Высотное кольцо Тагила». Сегодня Нижний Тагил выглядит так (рис. 1). На сегодняшний момент введен в эксплуатацию жилой комплекс «Чистые пруды», состоящего из группы 16-ти этажных зданий, запущено в строительство несколько проектов многоэтажных зданий: 3-х 16-ти этажных домов «Абсолют», «Премьер» и «Победа», бизнес-центр «Островский». 

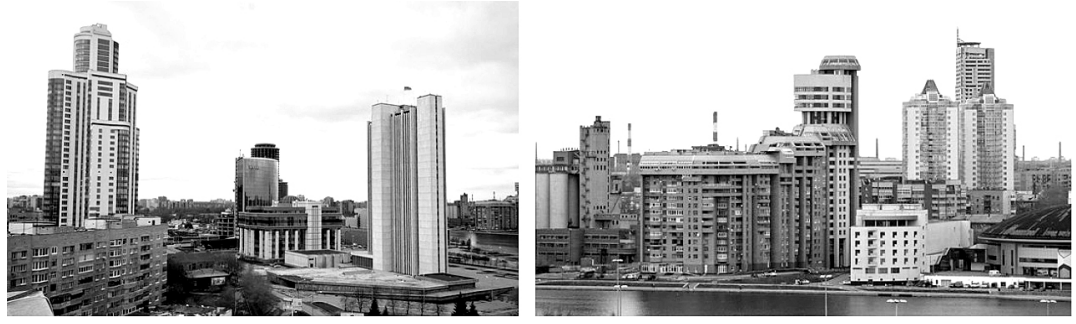

Рис. 1. Виды на городскую среду Нижнего Тагила

Знаменитый гостиничный оператор «Radisson» вместо ранее запланированного Екатеринбурга анонсировал строительство высотного отеля «Опера» в Нижнем Тагиле на улице Малышева (рис. 2).

Нижневартовску был присвоен статус города в 1972 году. Однако первое поселение Нижне-Вартовское появилось на берегу Оби еще в 1913 г.

Архитектура Нижневартовска мало малопривлекательна для туристов, похожа на московский спальный район.

Т.к. город относительно молодой, то основную массу жилых

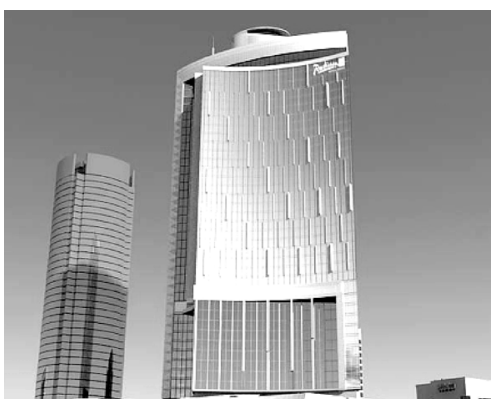

Рис. 2. Проект отеля "Опера" зданий составляют дома от 9-ти до 16-ти этажей (рис. 3). В городе есть только два наиболее высотных здания в 25 этажей (рис. 3, фото слева)
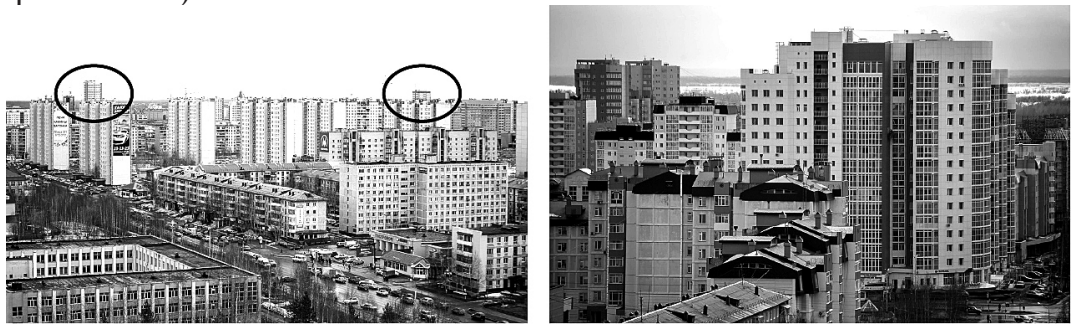

Рис. 3. Виды на городскую среду Нижневартовска 
История города Сургута началась с 1594 года, первый камень которого был заложен на берегу Оби сыном Ивана Грозного Федором Иоанычем. После мятежа кулаков и его подавления в 1920 году Сургут лишили статуса города и он стал селом. И только после добычи первой нефти в 1965 году Сургут снова получил статус города. Водная артерия Сургута - река Сайма. В отличие от других крупных городов УрФО с населением от 250 до 500 тысяч жителей Сургут богат на высотные здания. Вот некоторые из них (рис. 4, слева на право): жилой 16-ти этажный дом с мансардой по ул. Университетской, 3; ЖК «Александрия» (18 этажей по высокой стороне комплекса); высотные дома в новостройке Сургута; ЖК «Акварель» по ул. И. Захарова, 19; ЖК «Возрождение» на ул. Мелик-Карамова, 23А; ЖК «4 сезона» в 39 микрорайоне города;
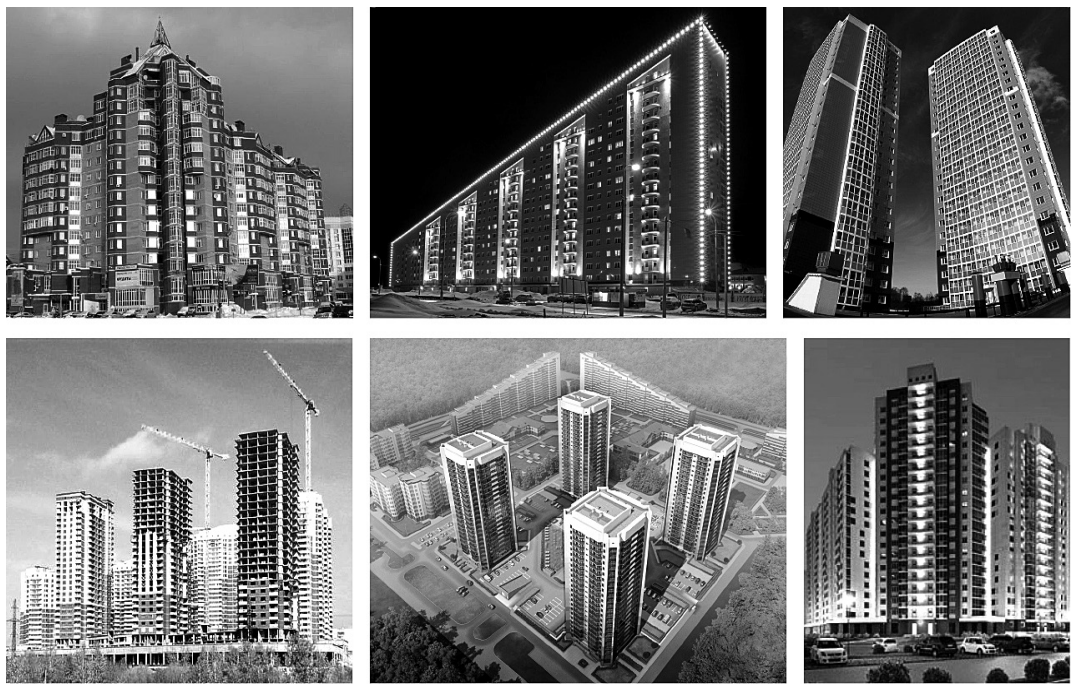

Рис. 4. Высотные здания г. Сургута

Продолжить список могут также высотные дома: жилой 16-ти этажный дом по ул. Университетской, 7; ЖК «Жемчужина Югры» по ул. Игоря Киртбая, 37; ЖК «Северная Венеция» по ул. Уни- 
верситетской, 33. В 2013 году начат масштабный проект группы компаний «Сибпромстрой» строительства самого высотного здания в Ханты-Мансийском автономном округе.

Его высота составит около 120 метров (40 этажей), которое планируется сдать в эксплуатацию в 2018 году. По классификации экспертной коллегии Emporis это здание можно отнести к небоскребам.

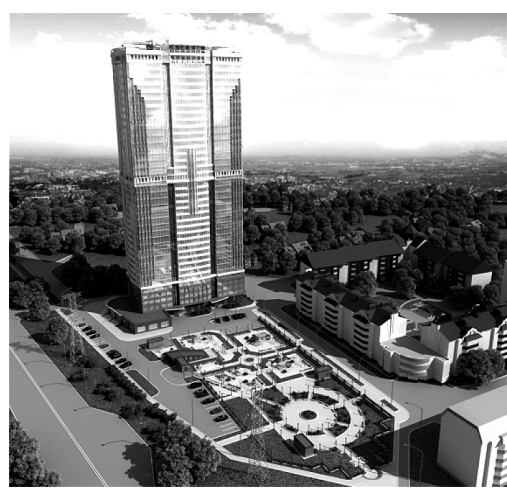

Рис. 5. Проект высотного 40-ка этажного дома в г. Сургут

Магнитогорск - это город на реке Урал, план которого организован по схеме промышленного соцгорода: селитебная зона расположена вокруг промышленного района и изолирована санитарно-защитной зоной. Весь город делится на три района, со сложившейся городской застройкой. Город сегодня активно развивается в южном направлении, но эта территория тоже имеет границы. Поэтому в настоящее время, с точки зрения экономики и, учитывая острую нехватку земельных ресурсов и возросшую цену на землю, городское строительство г. Магнитогорска должно быть ориентировано на высотные здания.
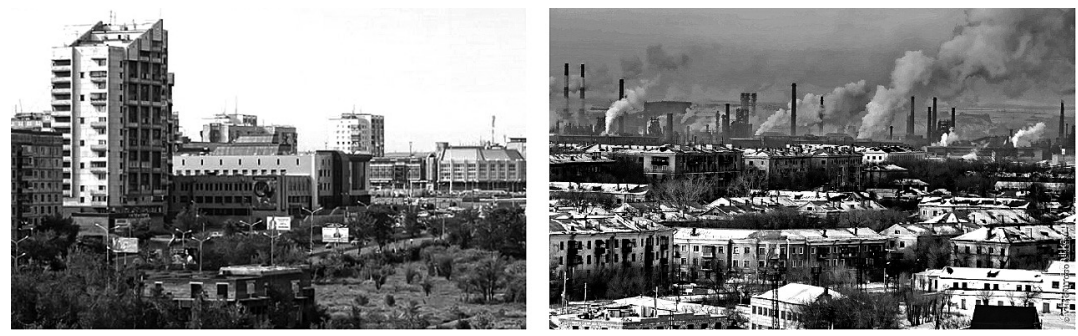

Рис. 6. Вид на городскую среду г. Магнитогорска

В основной массе максимальная этажность городской застройки составляет 16 этажей (рис. 6). Были построены два 17-этаж- 
ных в 142а микрорайоне, на пересечении улиц Труда и Тевосяна. Высотную динамику городу задают трубы Магнитогорского металлургического комбината. Из наследия 2000-х гг. выделяется строившийся 15 лет у Южного моста внушительный Вознесенский собор высотой до 60 метров (рис. 7).

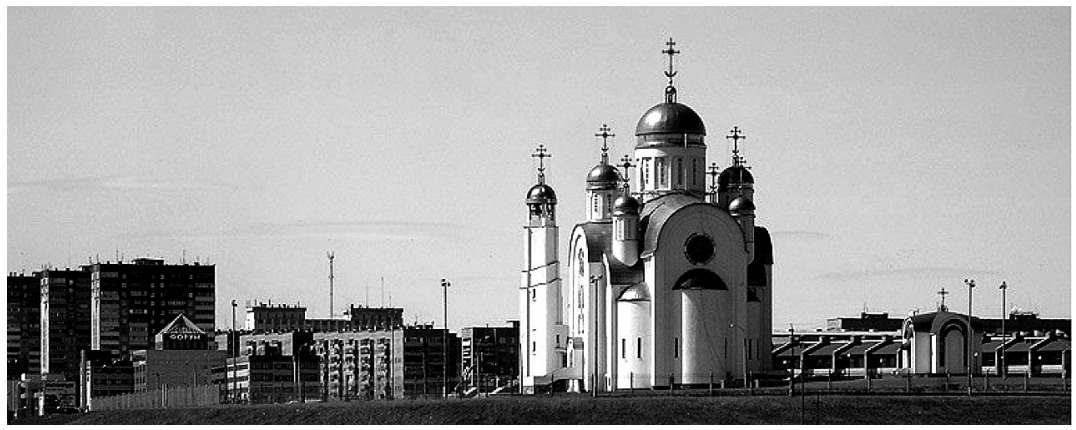

Рис. 7. Храм Вознесения Господня, г. Магнитогорск

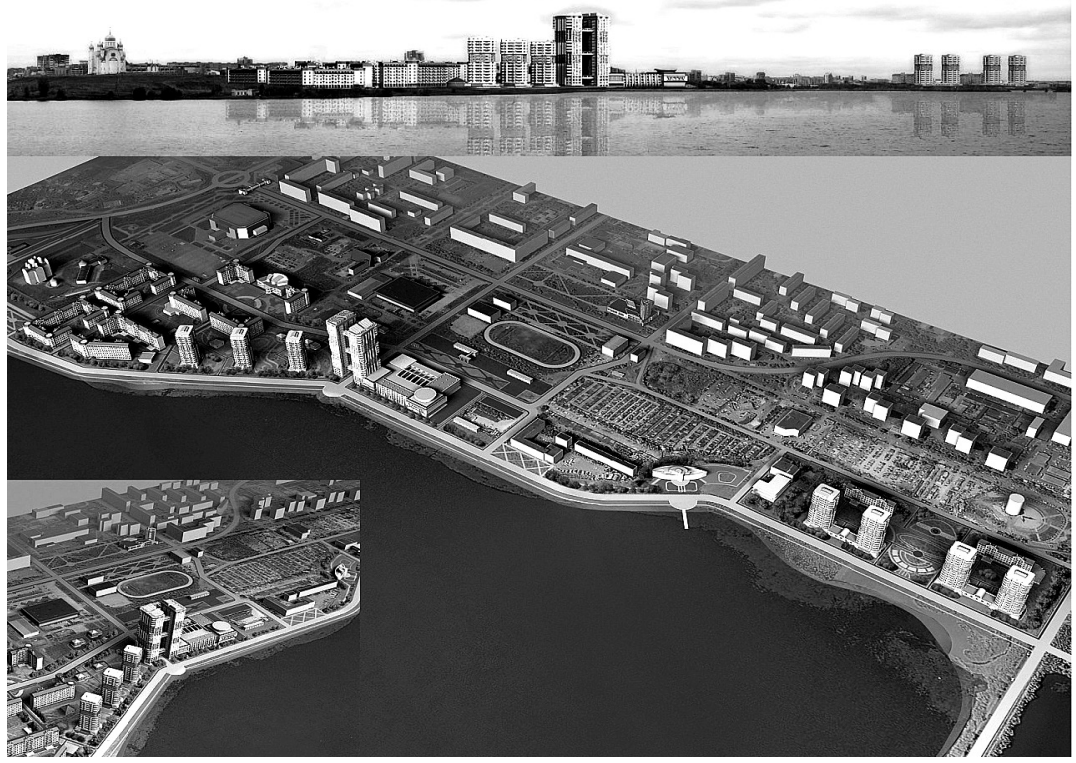

Рис. 8. Эскиз проекта застройки по улице Вознесенская, арх. Виктор Николаев, АБП "Главпроект" 
Сегодня существуют проекты, выполненные молодыми архитекторами города, включающие высотные здания, превышающие 17 этажей (рис. 8).

На наш, взгляд сегодня все более актуальной становиться проблема высотного строительства в крупных городах УрФО, которое диктуют следующие факторы:

- необходимость формирования силуэтных характеристик, высотных акцентов городской застройки;

- отсутствие резерва свободных территорий для развития строительства в городах, позволяющих размещение значительных объёмов в составе единого градостроительного комплекса;

- наличие потенциальных покупателей на квартиры в высотных домах;

- созданием высотных доминант с выразительным и запоминающимся архитектурным решением, являющимся «визитной карточкой» города;

- возможность иметь в пределах одного участка территории многофункциональный комплекс, зонированный по вертикали;

- современные строительные технологиями, позволяющими обеспечить высотное строительство.

Однако высотное строительство в городах ложится бременем на инженерные коммуникации, и если при новостройках на уровне 11 этажей надолго образуются уличные пробки, то с возведением зданий в 25 этажей проблема может стать неразрешимой.

На плане г. Магнитогорска (рис. 9) представлен анализ градостроительной ситуации г. Магнитогорска, где отмечены возможные, наиболее вероятные и предлагаемые места для расположения высотных зданий на пересечении или завершении осей улиц. Кроме градостроительного анализа выбор месторасположения и этажность проектируемых высотных зданий в г. Магнитогорске должно основываться также на анализ сложившейся (исторической) городской застройки и особенности «экоклимата» и «экопогоды» в городе. 


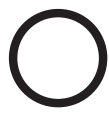

- предлагаемые места проектирования высотных домов на основе анализа главных композиционных осей.

$\bigcirc$

- наиболее вероятные места для проектирования высотных домов, располагаемых на пересечении или завершении осей, как правило, это площади, пересечение основных дорог, исторически значимые места.

- возможные места проектирования высотных зданий, они располагаются на пересечении или завершении осей улиц.

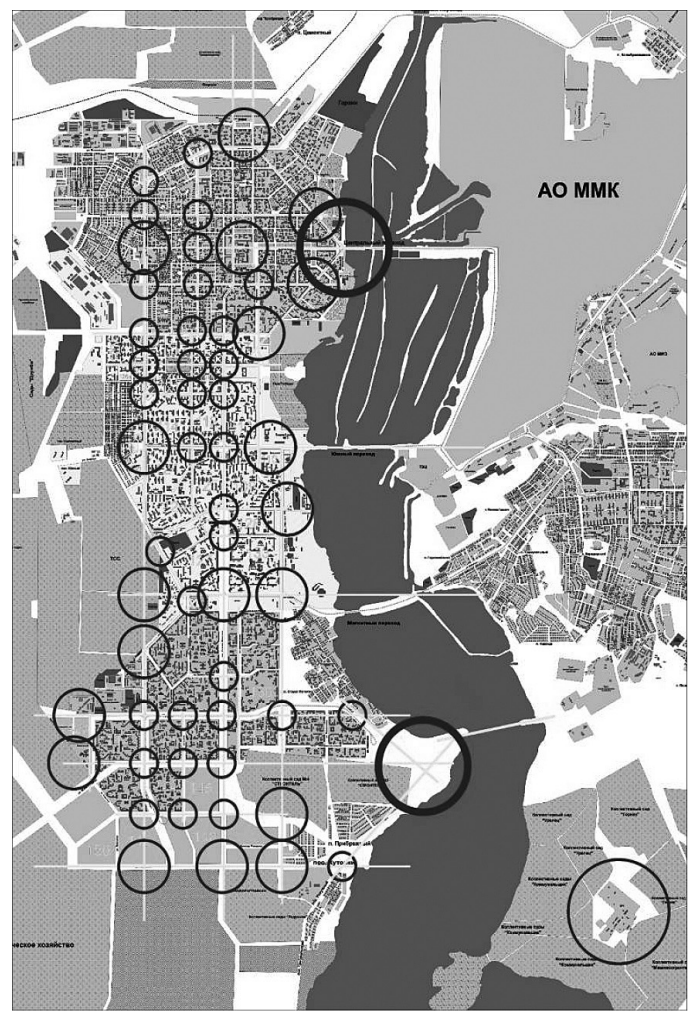

\section{Список литературы}

1. Архитектура и эмоциональный мир человека / Г.Б. Забельшанский, Г.Б. Миневрин, А.Г. Раппапорт, Г.Ю. Сомов. М.: Стройиздат, 1985.208 с.

2. Булатова Е.К., Ульчицкий О.А. Малые и средние южноуральские города: основные проблемы и пути развития действительности // Архитектура. Строительство. Образование: ФГБОУ ВПО «Магнитогорский государственный технический университет им. Г.И. Носова». Магнитогорск, 2013. С. 120-125.

3. Города Уральского Федерального округа // Викепидия [Электронный ресурс] URL: https://ru.wikipedia.org/wiki/Города_Уральского_федерального_округа (дата обращения 11.01.2017). 
4. Граник Ю.Г., Магай А.А., Дубынин Н.В. и др. Архитектурно-технические решения нового типа энергосберегающего высотного 35-ти этажного жилого дома / Под ред. Ю.Г. Граник. М.: ОАО ЦНИИЭП жилища, 2004. 31 с.

5. В центре Кургана хотят построить 25-этажный дом. Из-за небоскреба назревает конфликт [Электронный ресурс]. URL: http:// ura.ru/news/1052264134 (дата обращения 12.01.2017).

6. Горохов Д. Перспективы высотного строительства в Челябинской области // Стройэксперт [Электронный ресурс]. URL: http:// expert74.com/nomer.php?art=71 (дата обращения 7.12.2016).

7. История Сургута [Электронный ресурc]. URL: http://www.101hotels.ru/recreation/russia/surgut/history (дата обращения 12.01.2017).

8. Каюмова Н.А. Православное храмостроение в России в современных условиях//Научные труды SWorld. 2013. Т. 39. № 2. С. 39-45.

9. Магай А.А., Дубынин Н.В. Архитектурно-художественный облик высотных зданий // Архитектура и строительство России. 2009. № 4. C. 22-29.

10.Проблемы становления высотного строительства в России // Стройка: Санкт-Петербург [Электронный ресурс]. URL: http:// library.stroit.ru/articles/verhstroy/ (дата обращения 13.01.2017)

11. Усатая Т.В., Шенцова О.М. Основы проектирования архитектурной среды. Магнитогорск: Изд-во Магнитогорского госуд. техн. ун-та им. Г.И. Носова, 2008.

12. Федосихин В.С., Хорошанский В.В. Магнитогорск - классика советской социалистической архитектуры 1918-1991 гг. / Под ред. В.С. Федосихина. Магнитогорск: МГТУ им. Г.И. Носова, 1999.

13. Хасиева С.А. Архитектура городской среды: учеб. для вузов. М.: Стройиздат, 2001. 200 с.

14. Шенцова О.М. Высотные здания в объемно-пространственной композиции городской среды // Архитектура. Строительство. Образование, 2016. № 1 (7). С. 102-110.

15.Шенцова О.М., Хисматуллина Д.Д., Федосихин В.С. Профессиональная подготовка архитекторов в Магнитогорске для создания комфортной жилой среды города // Жилищное строительство. 2012. № 5. C. 9-12. 


\section{References}

1. Zabel'shanskiy G.B., Minevrin G.B., Rappaport A.G., Somov G.Yu. Arkhitektura i emotsional'nyy mir cheloveka [Architecture and emotional world of the person]. M.: Stroyizdat, 1985. 208 p.

2. Bulatova E.K., Ul'chitskiy O.A. Malye i srednie yuzhnoural'skie goroda: osnovnye problemy i puti razvitiya deystvitel'nosti [Small and average South Ural cities: main problems and ways of development of reality]. Arkhitektura. Stroitel'stvo. Obrazovanie [Architecture. Construction. Education]. Magnitogorsk, 2013, pp. 120-125.

3. Goroda Ural'skogo Federal'nogo okruga [Cities of the Ural Federal District]. Vikepidiya. https://ru.wikipedia.org/wiki/Goroda_Ural'skogo_federal'nogo_okruga

4. Granik Yu.G., Magay A.A., Dubynin N.V. et al. Arkhitekturno-tekhnicheskie resheniya novogo tipa energosberegayushchego vysotnogo 35-ti etazhnogo zhilogo doma [Architectural technical solutions of new type energy saving high-rise 35 floor houses] / Yu.G. Granik (ed.). M.: OAO TsNIIEP zhilishcha, 2004. 31 p.

5. V tsentre Kurgana khotyat postroit' 25-etazhnyy dom. Iz-za neboskreba nazrevaet konflikt [In the center of Kurgan want to build the 25-storey house. Because of a skyscraper the conflict]. http:// ura.ru/news/1052264134

6. Gorokhov D. Perspektivy vysotnogo stroitel'stva v Chelyabinskoy oblasti [Prospects for high-rise construction in the Chelyabinsk region]. Stroyekspert. http://expert74.com/nomer.php?art=71

7. Istoriya Surguta [History of Surgut]. http://www.101hotels.ru/recreation/russia/surgut/history

8. Kayumova N.A. Pravoslavnoe khramostroenie v Rossii v sovremennykh usloviyakh [An orthodox hramostroyeniye in Russia in modern conditions]. Nauchnye trudy SWorld [Scientific works of SWorld]. 2013. V. 39. № 2, pp. 39-45.

9. Magay A.A., Dubynin N.V. Arkhitekturno-khudozhestvennyy oblik vysotnykh zdaniy [The architectural and art image of high-rise buildings]. Arkhitektura i stroitel'stvo Rossii [Architecture and construction of Russia]. 2009. № 4, pp. 22-29. 
10. Problemy stanovleniya vysotnogo stroitel'stva v Rossii [Problems of formation of high-rise construction in Russia]. Stroyka: Sankt-Peterburg [Building: St. Petersburg]. http://library.stroit.ru/articles/verhstroy/

11. Usataya T.V., Shentsova O.M. Osnovy proektirovaniya arkhitekturnoy sredy [Bases of design of the architectural environment]. Magnitogorsk, 2008.

12.Fedosikhin V.S, Khoroshanskiy V.V. Magnitogorsk - klassika sovetskoy sotsialisticheskoy arkhitektury 1918-1991 g.g. [Magnitogorsk - the classic of the Soviet socialist architecture of 19181991] / V.S. Fedosikhin (ed.). Magnitogorsk: MGTU im. G.I. Nosova, 1999.

13. Khasieva S.A. Arkhitektura gorodskoy sredy [Arkhitektur of the urban environment]. M.: Stroyizdat, 2001. 200 p.

14. Shentsova O.M. Vysotnye zdaniya v obemno-prostranstvennoy kompozitsii gorodskoy sredy [High-rise buildings in volume and spatial composition of the urban environment]. Arkhitektura. Stroitel'stvo. Obrazovanie [Architecture. Construction. Education], 2016. № 1 (7), pp. 102-110.

15.Shentsova O.M., Khismatullina D.D., Fedosikhin V.S. Professional'naya podgotovka arkhitektorov v Magnitogorske dlya sozdaniya komfortnoy zhiloy sredy goroda [Vocational training of architects in Magnitogorsk for creation of the comfortable inhabited environment of the city]. Zhilishchnoe stroitel'stvo [Housing construction]. 2012. № 5, pp. 9-12.

\section{ДАННЫЕ ОБ АВТОРАХ}

Шенцова Ольга Михайловна, кандидат педагогических наук, доцент

Магнитогорский государственный технический университет им. Г.И. Носова

пр. Ленина, 38, 455000, г. Магнитогорск, Российская Федеращчия

shenolga@yandex.ru 
Федосихин Владимир Сергеевич, доктор технических наук, профессор

Магнитогорский государственный технический университет им. Г.И. Носова

пр. Ленина, 38, 455000, г. Магнитогорск, Российская Федеращиия

FedosVS@yandex.ru

\section{DATA ABOUT THE AUTHORS}

Shentsova Olga Mikhaylovna, Candidate of the Pedagogical Sciences, Assistant Professor

Nosov Magnitogorsk State Technical University

38, Lenin Ave., Magnitogorsk, 455000, Russian Federation shenolga@yandex.ru

Fedosikhin Vladimir Sergeevich, Doctor of Technical Sciences, Professor

Nosov Magnitogorsk State Technical University

38, Lenin Ave., Magnitogorsk, 455000, Russian Federation

FedosVS@yandex.ru 